\title{
PENINGKATAN AKTIFITAS DAN HASIL BELAJAR GEOGRAFI MATERI LITOSFER MELALUI PENERAPAN MODEL TEAMS GAMES TOURNAMENS (TGT) DI SMAN 3 PATI
}

\section{IMPROVEMENT OF ACTIVENESS AND LITHOSPHERIC MATERIAL GEOGRAPHY LEARNING OUTCOMES THROUGH THE APPLICATION OF TEAMS GAMES TOURNAMENTS MODELS ON SMAN 3 PATI}

\author{
Yayuk Ismirahayu \\ Sekolah Menengah Atas Negeri 3 Pati \\ Email : ismismaga@gmail.com
}

Naskah Diterima : 19 Mei 2017

\begin{abstract}
Pre-test results of the lithospheric material geography class X IPS (social science) 3 SMAN 3 Pati semester 2 year 2015/2016 have achievement of the students still low. The research aims to : (1) improve the learning activities through the application of Teams Games Tournaments models class X IPS 3 SMAN 3 Pati semester 2 year 2015/2016, (2) improve the learning outcomes through the application of Teams Games Tournaments models class X IPS 3 SMAN 3 Pati semester 2 year 2015/2016. The Class Action Research was conducted with cycles I and II. Implementation of the action in the first cycle and II include : Planning, Acting, Observing, and Reflecting. The research result are (1) learning activity at linitial condition was low $78 \%$ and medium $22 \%$, student activity cycle I was low $22 \%$, medium 56\%, high $22 \%$, cycle II student activity was $56 \%$, and high $44 \%$. (2) Learning outcomes showed improvement from the initial condition of the completeness of 5 students $(14 \%)$, cycle II of the completeness of 22 students (61\%) and cycle II of the completeness of 36 students (100\%). From the initial condition to the treatment of action cycle I there was an increase of $47 \%$ and from cycle I to cycle II there was an increase of $53 \%$.
\end{abstract}

Keywords: learning activities, learning outcomes, class action research, teams games tournaments

\begin{abstract}
ABSTRAK
Pretes hasil belajar Geografi materi Litosfer kelas X IPS 3 semester 2 SMAN 3 Pati tahun 2015/2016 memiliki keaktifan belajar siswa masih rendah. Tujuan penelitian : (1) untuk meningkatkan aktifitas belajar melalui penerapan pembelajaran Model Teams Games Tournaments (TGT) siswa kelas X IPS 3 SMAN 3 Pati tahun pelajaran 2015/2016; (2) untuk meningkatkan hasil belajar melalui penerapan pembelajaran Model Teams Games Tournaments (TGT) siswa kelas X IPS 3 SMAN 3 Pati tahun pelajaran 2015/2016. Penelitian Tindakan Kelas (Action Research) ini dilaksanakan dengan siklus I dan II. Pelaksanaan tindakan pada siklus I dan II meliputi : Perencanaan (Planning), Pelaksanaan (Acting), Observasi (Observing), dan Refleksi (Reflecting). Hasil penelitian yaitu (1) keaktifan belajar pada kondisi awal rendah $78 \%$ dan sedang $22 \%$, siklus I keaktifan siswa rendah $22 \%$, sedang 56\%, tinggi 22\%, siklus II keaktifan siswa sedang 56\%, dan tinggi 44\%. (2) Hasil belajar siswa menunjukkan peningkatan dari kondisi awal ketuntasan 5 siswa (14\%), siklus I ketuntasan 22 siswa (61\%) dan siklus II ketuntasan 36 siswa (100\%). Dari kondisi awal ke perlakuan tindakan siklus I ada kenaikan sebesar $47 \%$ dan dari siklus I ke siklus II ada kenaikan sebesar $53 \%$.
\end{abstract}

Kata kunci : keaktifan belajar, hasil belajar, penelitian tindakan kelas, teams games tournaments 


\section{PENDAHULUAN}

Mata Pelajaran Geografi di SMA pada Standar Kompetensi menganalisis Litosfer, Kompetensi Dasar menganalisis perkembangan Litosfer kelas X semester 2 merupakan salah satu materi penting yang selalu dikeluarkan pada ujian nasional. Setelah dilakukan pretes hasil belajar Geografi materi Litosfer kelas X IPS 3 semester 2 SMAN 3 Pati tahun 2015/2016 diperoleh hasil belajar diatas KKM 75 hanya 5 siswa (14\%), siswa yang belum mencapai KKM 75 sebanyak 31 siswa (86\%) dari 36 orang. Hal ini disebabkan keaktifan siswa dalam proses pembelajaran yang masih rendah.

Pembelajaran Geografi pada materi Litosfer berkesan kurang menarik, membosankan, dan hafalan. Materi Litosfer memiliki sifat selain hafalan juga cenderung pemahaman, membedakan Litosfer yang satu dengan lainnya serta cenderung memberikan contoh dalam kehidupan sehari-hari. Tetapi yang terjadi proses pembelajaran selama ini masih menggunakan metode konservatif, ceramah dan diskusi kecil yang membosankan. Siswa merasa menganggur, pasif dan hafalnya menjadikan siswa mengantuk.

Untuk itu perlu dilakukan Penelitian Tindakan Kelas dengan menerapkan berbagai upaya inovatif dan kreatif dari semua komponen pembelajaran yang meliputi siswa, lingkungan sekolah, sarana belajar, dan faktor guru dengan berbagai model pembelajarannya. Hal ini dilakukan dengan harapan pelaksanaan program belajar yang menyenangkan dan mengarah pada Pengajaran Aktif,
Inovatif, Kreatif, Efektif dan Menyenangkan (PAIKEM).

Tujuan penelitian ini adalah : (1) untuk meningkatkan aktifitas melalui penerapan Model Teams Games Tournaments (TGT) siswa kelas X IPS 3 SMA Negeri 3 Pati tahun pelajaran 2015/2016; (2) untuk meningkatkan hasil belajar melalui penerapan Model Teams Games Tournaments (TGT) siswa kelas $\mathrm{X}$ IPS 3 SMA Negeri 3 Pati tahun pelajaran 2015/2016.

\section{TINJAUAN PUSTAKA}

\section{Model Teams Games Tournamens (TGT)}

Model Teams Games Tournamens (TGT) adalah suatu model pembelajaran yang mengembangkan pendekatan kerjasama antar kelompok, dalam pembelajaran ini siswa memainkan permainan dengan anggota-anggota tim lain untuk memperoleh tambahan point pada skor tim mereka.

Dalam permainan ini mengandung persaingan menurut aturan yang ditetapkan. Dalam penelitian ini istilah Teams Games Tournamens disingkat dengan nama TGT. Kelebihan TGT adalah bermanfaat dalam mengajarkan aspek-aspek kognitif dengan adanya persaingan untuk mendapatkan kemenangan maka menimbulkan motivasi kuat, menyenangkan dan berpengaruh pada kecepatan penyerapan materi.Komponen pembelajaran TGT yaitu :

\section{Presentasi \\ Kelas/Pengamaan langsung}

Komponen ini digunakan guru untuk memperkenalkan materi pelajaran. 
Siswa harus memperhatikan secara cermat dan mencatat hal-hal penting yang berkaitan dengan materi pelajaran, karena sangat menunjang keberhasilan belajar dan akan menentukan nilai tim mereka.

\section{Belajar tim}

Tim terdiri dari 4 sampai 5 siswa yang memiliki kemampuan yang berbeda. Setelah guru menyajikan materi pelajaran, tim melakukan belajar bersama dilanjutkan diskusi antar anggota untuk mengevaluasi hasil belajar timnya untuk mempersiapakan pertandingan. Tim harus memberikan perhatian dan penghargaan yang sama terhadap setiap anggota sehingga timbul rasa saling menghargai bagi setiap anggota.

\section{Turnamen/Pertandingan}

Pertandingan dilaksanakan setelah guru memberikan materi untuk menguji pengetahuan yang dicapai siswa dan disusun dalam pertanyaan yang relevan dengan materi dalam presentasi kelas. Permainan dilakukan oleh 4 atau 5 siswa yang berkemampuan sama dan masingmasing mewaklili dari tim yang berbeda.

\section{Penghargaan tim}

Tim yang berhasil mendapatkan nilai/skor tertinggi diberipenghargaan/hadiah berupa buku atau alat tulis.

Langkah-langkah pembelajaran Teams Games Tournamens (TGT) : (a) tahap pemberian materi pelajaran; (b) tahap pembagian kelompok (Tim); (c) tahap persiapan permainan; (d) tahap permainan dan pertandingan. Permainan dilakukan dengan menggunakan roda impian.

Langkah-langkah aktifitas pembelajaran meliputi : (1) tiap-tiap tim mendapat giliran memutar roda impian untuk menentukan kartu soal yang dipilih, kemudian menjawab pertanyaan yang muncul; (2) jika dalam tim tidak ada yang dapat menjawab, maka pertanyaan dilempar kepada kelompok lain dibawahnya dan bila kelompok dibawahnya dapat menjawab maka skor nilai diberikan pada kelompok yang bisa menjawab; (3) roda impian dapat diputar oleh tiap-tiap tim untuk mendapat pertanyaan sampai habis. Kartu permainan dapat berupa kartu soal, kartu bonus, kartu hadiah, kunci jawaban, kartu permainan dan menentukan pemandu permainan; (4) pemandu permainan mengumumkan hasil nilai tim yang telah terkumpul.

\section{Keaktifan Belajar}

Dierich dalam Nasution (1995) mengelompokkan aktifitas siswa ke dalam kategori : Visual Activities, oral activities, listening activities, writing activities, drawing activities, motor activities, mental activities, dan emotional activities. Keaktifan belajar meliputi aktif menjawab pertanyaan, mengajukan pertanyaan, memperhatikan gambar, diskusi, kerjasama kelompok, interaksi, mengeluarkan pendapat, mengingat, memahami, memecahakan soal dan menganalisis. Aktifitas belajar materi kelompok sosial ini terfokus pada 
diskusi, kerjasama kelompok dan keaktifan.

Jadi dalam proses belajar mengajar harus menumbuhkan suasana yang kondusif sehingga siswa aktif bertanya, mempertanyakan dan menumbuhkan gagasan. Belajar mengajarsebagai proses aktif dari pembelajar dan yang memberikan pembelajaran dalam membangun kognitif, afektif dan psikomotorik siswa, yang meninggalkan proses pasif dengan pembelajaran hanya satu arah saja.

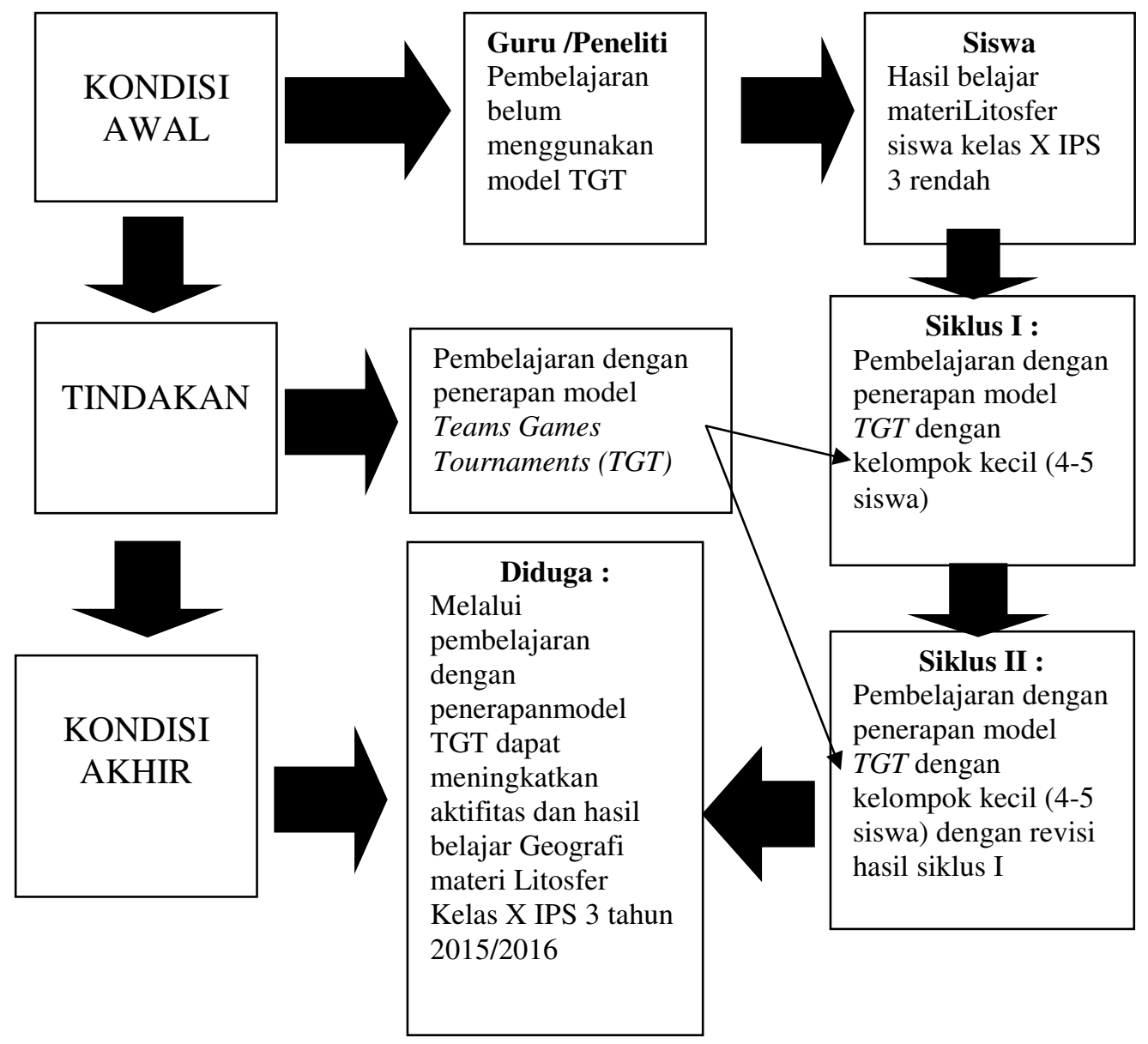

\section{Gambar 1.}

Bagan Kerangka Pikir 


\section{Hipotesis Tindakan}

Untuk menjawab permasalahan yang diajukan serta guna mencapai tujuan penelitian, maka disusun hipotesis tindakan : (1) melalui penerapan Model Teams Games Tournaments (TGT) dapat meningkatkan keaktifan belajar Geografi materi Litosfer siswa kelas X IPS 3 SMAN 3 Pati tahun pelajaran 2015/2016; (2) melalui penerapan Model Teams Games Tournaments (TGT) dapat meningkatkan hasil belajar Geografi materi Litosfer siswa kelas X IPS 3 SMAN 3 Pati tahun pelajaran 2015/2016.

\section{METODE PENELITIAN}

Waktu penelitian dilaksanakan pada bulan Januari sampai dengan April semester 2 tahun pelajaran 2015/2016. Penelitian Tindakan Kelas ini dilakukan di SMAN 3 Pati. Subyek penelitian adalah siswa kelas X IPS 3 berjumlah 36 orang dengan perincian siswa laki-laki 16 orang dan perempuan 18 orang semester 2 SMAN 3 Pati tahun pelajaran 2015/2016.

Sumber data yaitu data yang berasal dari subyek penelitian ini sebagai sumber data primer : (1) data awal dari subyek penelitian yang berupa hasil pretes sebagai data kondisi awal; (2) data hasil tes pada siklus I; (3) data hasil tes pada siklus II.

Teknik pengumpulan data meliputi dokumentasi, observasi, dan tes. Teknik tes ada 3 kali tes tertulis,: (1) soal pretes terdiri 5 soal uraian; (2) soal akhir siklus I terdiri 5 soal uraian; (3) soal akhir siklus II terdiri 5 soal uraian. Alat pengumpul data berupa butir soal tes uraian, lembar observasi/pengamatan, dan dokumentasi buku nilai hasil belajar.

Validasi data dilakukan dengan triangulasi sumber. Penelitian ini merupakan Penelitian Tindakan Kelas (PTK), menurut Aqib (2008) dan Wiraatmadja (2008), Penelitian Tindaka Kelas (PTK) ada 4 (empat) tahapan dalam penelitian tindakan kelas yaitu perencanaan (planning), pelaksanaan (acting), observasi (observing), dan refleksi (reflecting). Model pembelajaran yang diterapkan adalam Teams Games Tournamens (TGT). Prosedur Penelitian tindakan Kelas (PTK) disajikan pada Gambar 2.

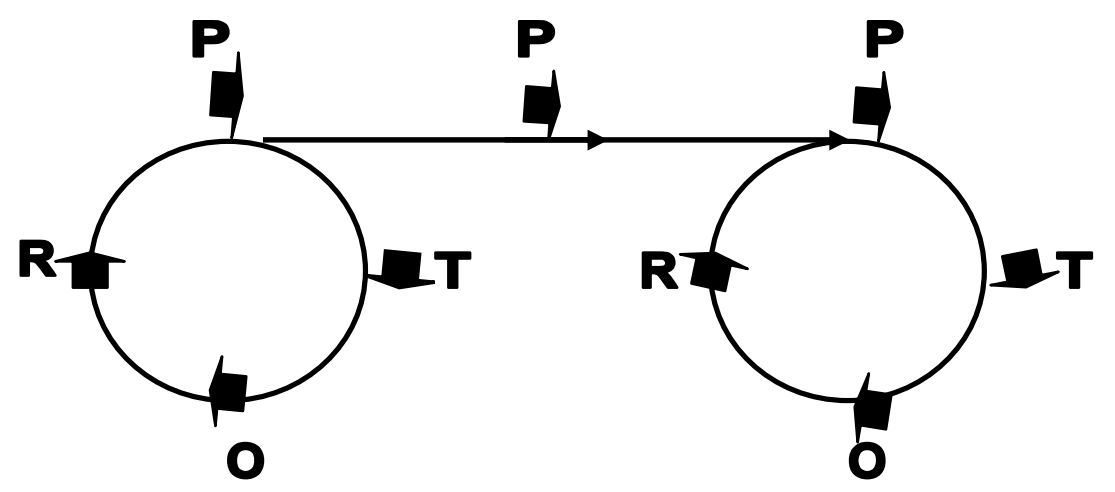

Keterangan $: \mathrm{P}=$ Perencanaan $\mathrm{T}=$ Tindakan $\mathrm{O}=$ Observasi $\mathrm{R}=$ Refleksi

Gambar 2.

Siklus Penelitian Tindakan Kelas (PTK) 


\section{Analisis Data}

Rencana Siklus I membuat perangkat pembelajaran meliputi Silabus, RPP, dan alat penilaian. Tahap pelaksanaan tindakan yaitu menerapkan rencana tindakan pembelajaran model TGT dengan langkah-langkah pembelajaran sebagai berikut : (a) tahap pemberian materi pelajaran; (b) tahap pembagian kelompok (tim) tiap kelompok terdiri atas 4 siswa; (c) tahap persiapan permainan; (d) tahap permainan dan pertandingan.

Langkah-langkah aktifitas pembelajaran meliputi : tiap-tiap tim mendapat giliran memutar roda impian untuk menentukan kartu soal yang dipilih, kemudian menjawab pertanyaan yang muncul. Jika dalam tim tidak ada yang dapat menjawab, maka pertanyaan dilempar kepada kelompok selanjutnya dan bila kelompok tersebut dapat menjawab maka skor nilai diberikan pada kelompok yang bisa menjawab soal. Roda impian dapat diputar oleh tiap-tiap tim untuk mendapat pertanyaan sampai habis. Kartu permainan dapat berupa kartu soal, kartu bonus, kartu hadiah, kunci jawaban, kartu permainan dan menentukan pemandu permainan. Pemandu permainan mengumumkan hasil nilai tim yang telah terkumpul.

Tahap observasi/pengamatan dilakukan oleh guru mitra/teman sejawat yang bertugas melaksanakan pengamatan dengan bantuan lembar observasi untuk mengamati keaktifan siswa. Tahap refleksi, hasil pembelajaran dibahas peneliti dengan guru mitra/teman sejawat kekurangan-kekurangan dalam tindakan. Rencana Siklus II perlakuannya sama dengan Rencana Siklus I hanya pelaksanaannya ada revisi.

\section{HASIL DAN PEMBAHASAN}

Kondisi awal menunjukkan dalam pengamatan proses pembelajaran siswa tidak aktif belajar, merasa bosan, mengantuk dan berbicara sendiri. Komunikasi pembelajaran terfokus pada guru, suasana hening, tidak ada siswa yang bertanya maupun menyatakan bahwa dirinya belum paham terhadap materi yang diberikan guru. Berdasarkan laporan hasil observasi dari kolaboran, diperoleh keaktifan siswa sebagaimana disajikan pada Tabel 1.

Tabel 1 menunjukan bahwa siswa dengan keaktifan rendah sebanyak 28 siswa atau $78 \%$ sedangkan siswa dengan keaktifan sedang sebanyak 8 siswa atau $22 \%$. Hal ini menunjukkan bahwa terdapat kurang dari sepertiga siswa di kelas yang tidak fokus dalam belajar. Hal ini berdampak pada hasil belajarnya. Setelah dilakukan pretes pada kondisi awal hasil belajar siswa dapat dilihat pada Tabel 2.

Tabel 1.

Keaktifan Siswa Kondisi Awal

\begin{tabular}{ccc}
\hline Keaktifan & Jmh siswa & Persentase \\
\hline Rendah & 28 & 78 \\
Sedang & 8 & 22 \\
Tinggi & - & - \\
\hline Jumlah & 36 & 100 \\
\hline
\end{tabular}

Sumber : Pengolahan data (2017) 
Tabel 2.

Hasil Belajar Kondisi Awal

\begin{tabular}{cccc}
\hline Interval nilai & Jumlah Siswa & Persentase & Hasil Klasikal \\
\hline $40-54$ & 8 & 22 & Skor rata-rata: \\
$55-64$ & 10 & 28 & 50,50 \\
$65-74$ & 13 & 36 & KKM 75 \\
$75-84$ & 5 & 14 & \\
$85-94$ & - & - & \\
$95-100$ & - & - & \\
\hline Jumlah & 36 & 100 & \\
\hline
\end{tabular}

Tabel 2 menunjukkan siswa yang mendapatkan hasil belajar diatas $\mathrm{KKM}$ 75 hanya 5 siswa (14\%), siswa yang belum mencapai KKM 75 sebanyak 31 siswa $(86 \%)$ dari 36 orang. Berdasarkan laporan hasil observasi dari kolaboran/teman sejawat pada saat pelaksanaan proses pembelajaran maka diperoleh keaktifan siswa pada siklus I dapat dilihat pada Tabel 3.
Tabel 3 menunjukan bahwa siswa dengan keaktifan rendah tersisa 8 siswa (22\%), keaktifan sedang sebanyak 20 siswa $(56 \%)$, dan siswa dengan keaktifan tinggi sebanyak 8 siswa (22\%). Hal ini menunjukkan telah terjadi peningkatan keaktifan lebih dari dua pertiga siswa. Pada siklus I setelah diadakan tes diperoleh hasil belajar siswa dengan rentang nilai seperti pada Tabel 4.

Tabel 3.

Keaktifan Siswa pada Siklus I

\begin{tabular}{ccc}
\hline Keaktifan & Jmh siswa & Persentase \\
\hline Rendah & 8 & 22 \\
Sedang & 20 & 56 \\
Tinggi & 8 & 22 \\
\hline Jumlah & 36 & 100 \\
\hline Sumber : Pengolahan data $(2017)$ &
\end{tabular}

Tabel 4.

Hasil Belajar Siklus I Setelah Penerapan Model TGT

\begin{tabular}{cccc}
\hline Interval nilai & Jumlah Siswa & Persentase & Hasil Kalsikal \\
\hline $40-54$ & - & - & Skor rata-rata \\
$55-64$ & 1 & 3 & 70,50 \\
$65-74$ & 13 & 36 & KKM 75 \\
$75-84$ & 17 & 47 & \\
$85-94$ & 5 & 14 & \\
$95-100$ & - & - & \\
\hline Jumlah & 36 & 100 &
\end{tabular}


Tabel 4 menunjukkan bahwa dari nilai KKM 75 hasil belajar siswa terlihat meningkat dibanding dengan kondisi awal yaitu hanya 6 siswa $(17 \%)$ diatas KKM telah mengalami peningkatan menjadi 22 siswa (61\%). Selanjutnya berdasarkan laporan hasil observasi dari kolaboran/teman sejawat maka diperoleh keaktifan siswa pada siklus II seperti pada Tabel 5.

Tabel 5 menunjukan bahwa sudah tidak ada siswa dengan keaktifan rendah.
Jumlah siswa dengan keaktifan sedang sebanyak 20 siswa (56\%) dan siswa dengan keaktifan tinggi sebanyak 16 siswa (44\%). Terjadi peningkatan keaktifan pada keaktifan rendah ke keaktifan sedang meningkat 8 siswa, keaktifan sedang ke keaktifan tinggi meningkat 8 siswa. Berdasarkan tes hasil belajar pada siklus II setelah pelaksanaan tindakan melalui penerapan model TGT diperoleh hasil belajar dapat dilihat pada Tabel 6.

Tabel 5.

Keaktifan Siswa pada Siklus II

\begin{tabular}{ccc}
\hline Keaktifan & Jmh siswa & Persentase \\
\hline Rendah & - & - \\
Sedang & 20 & 56 \\
Tinggi & 16 & 44 \\
\hline Jumlah & 36 & 100 \\
\hline \multicolumn{2}{l}{ Sumber : Pengolahan data $(2017)$} &
\end{tabular}

Tabel 6.

Hasil Belajar pada Siklus II

\begin{tabular}{cccc}
\hline Interval nilai & Jumlah Siswa & Persentase & Hasil Kalsikal \\
\hline $40-54$ & - & - & Skor rata-rata \\
$55-64$ & - & - & 80,50 \\
$65-74$ & - & - & KKM 75 \\
$75-84$ & 16 & 44 & \\
$85-94$ & 10 & 28 & \\
$95-100$ & 10 & 28 & \\
\hline Jumlah & 36 & 100 &
\end{tabular}

Tabel 6 menunjukkan bahwa dari nilai KKM 75 hasil belajar siswa terlihat meningkat dibanding dengan kondisi pada siklus I yaitu terdapat 36 siswa $(100 \%)$ hasil belajar diatas KKM. Dengan demikian, pada pelaksanaan tindakan siklus II pembelajaran seluruh siswa dapat meningkatkan hasil belajar siswa dengan dibuktikan yaitu seluruh siswa memperoleh hasil belajar diatas KKM (100\%).

\section{KESIMPULAN DAN SARAN}

\section{Kesimpulan}

1. Melalui penerapan model Teams Games Tournamens (TGT) dapat meningkatkan keaktifan belajar dalam pembelajaran Geografi materi Litosfer 
siswa kelas X IPS 3 SMAN 3 Pati semester 2 tahun 2015/2016. Hal ini dibuktikan dengan pada kondisi awal keaktifan siswa rendah sebesar $78 \%$ dan sedang sebesar $22 \%$, siklus I keaktifan siswa rendah $22 \%$, sedang $56 \%$, tinggi $22 \%$, siklus II keaktifan siswa sedang $56 \%$, dan keaktifan siswa tinggi $44 \%$.

2. Hasil belajar siswa menunjukkan peningkatan dari kondisi awal ketuntasan sebanyak 5 siswa (14\%), siklus I ketuntasan 22 siswa (61\%) dan siklus II ketuntasan 36 siswa (100\%). Dari kondisi awal ke perlakuan tindakan siklus I ada kenaikan sebesar $47 \%$ dan dari siklus I ke siklus II ada kenaikan sebesar $53 \%$.

\section{Saran}

1. Bagi Guru : (a) Guru diharapkan dapat menerapkan model pembelajaran inovasi karena dapat meningkatkan keaktifan dan hasil belajar siswa; (b) Guru seharusnya lebih inovatif memilih dan menggunakan model yang sesuai.
2. Bagi siswa : (a) siswa belajar tidak hanya dengan menerima materi, menghafal, tetapi juga mempelajari sebagai proses yang harus dipahami dan diterapkan; (b) siswa diharapkan dapat belajar dengan aktif dalam mencari informasi untuk meningkatkan pengetahuan, pengalaman dan kemampuan berfikir kritis.

\section{DAFTAR PUSTAKA}

Aqib, Zainal. 2006. Penelitian Tindakan Kelas bagi Pengembangan Profesi Guru. Bandung : Yrama Widya.

Nasution. 2000. Didaktik Asas-asas Mengajar. Jakarta : Bumi Aksara.

Wiraatmadja, Rochiati. 2008. Metode Penelitian Tindakan Kelas. Bandung : PT Remaja Rosda Karya.

\section{BIODATA PENULIS}

Yayuk Ismirahayu, lahir di kota Pati Jawa Tengah pada 18 November 1972. Magister Pendidikan Kependudukan dan Lingkungan Hidup Universitas Sebelas Maret Surakarta Saat ini sebagai Guru Sosiologi di SMA N 3 Pati. 